\title{
CRITERIA DETERMINATION FOR OBSTACLE EFFECTIVENES EVALUATION
}

\author{
Tibor PALASIEWICZ, Jan KYJOVSKÝ \\ University of Defence, Brno, The Czech Republic \\ tibor.palasiewicz@unob.cz, jan.kyjovsky@unob.cz
}

\begin{abstract}
Up to date concept of warfare is characterized by a high mobility of units, in spite of this counter-mobility is currently disregarded. However, military engineers try to keep and develop this capability. One of the most important elements for the development in the field of counter-mobility is man-made obstacles effectiveness evaluation. The process of evaluation is applicable to the obstacle employment design, to the estimation of a battle progress as well as to the development of mine-laying means, including mines and explosives for obstacle creating. The article is focused on determination of the appropriate obstacles effectiveness evaluation criteria. The criteria can be applied within planning of barriers as well as other complexes of obstacles (obstacle areas, zones, belts), which allows to optimize the engagement of engineer units and means to fulfil the engineer tasks.
\end{abstract}

\section{Keywords: military engineering, military obstacles, effectiveness, evaluation, criteria}

\section{Introduction}

The publication AJP-3.2 Allied Joint Doctrine for Land Operations states that the fundamentals for all land operations are the manoeuvrist approach and mission command. The manoeuvrist approach is characterized as need to seize, retain and exploit the initiative. In combat, the manoeuvrist approach invariably includes elements of movement, firepower, and positional defence. There will almost always be a need to fix the enemy, deny him access to routes and objectives, and secure vital ground and key points. To fix is to deny the enemy his goals, to distract him and thus deprive him of his freedom of action [1].

It therefore follows that an obstacles are a significant support element of operation. Obstacles can significantly increase the effectiveness of own fires and decrease the possibility of movement in the area. Barriers are created in compliance with the intention of fighting, firing system, with a view to crossing ability in close relation to the existing obstacles with regard to the manoeuvre possibility of own forces and coordinate to create a coherent complex (barrier system) [2]. Barrier system is composed of explosive, nonexplosive and combined obstacles, destruction of objects and lines of communication. Explosive obstacles, mainly antitank minefields, are basic elements of barrier systems.

\section{Evaluation of obstacle effectiveness}

Obstacle effectiveness evaluation has wide application. Obstacle effectiveness means loss of ability to use terrain by enemy troops and reduce the success of their operation activities. Obstacle effectiveness is applicable to the obstacle employment design, to the estimation of a battle progress as well as to the development of minelaying means, including mines and explosives for obstacle creating. In 
commander decision-making process, effectiveness evaluation can be applied within planning of barriers as well as other complexes of obstacles (obstacle areas, zones, belts), which allows to optimize the engagement of engineer units and means to fulfil the engineer tasks. Obstacle effectiveness evaluation allows to select an optimal barrier according to the criteria considered, eventually choose the best technology (method) for barrier creation. In addition, requirements for parameters of barrier can follow from obstacle effectiveness evaluation.

Effectiveness can be defined as the ratio between the resolution of certain activities (outputs) and the cost of the activities (inputs) for a specific period. Expression of obstacle resolutions must be based on the general objectives of obstacle emplacement (Figure 1).

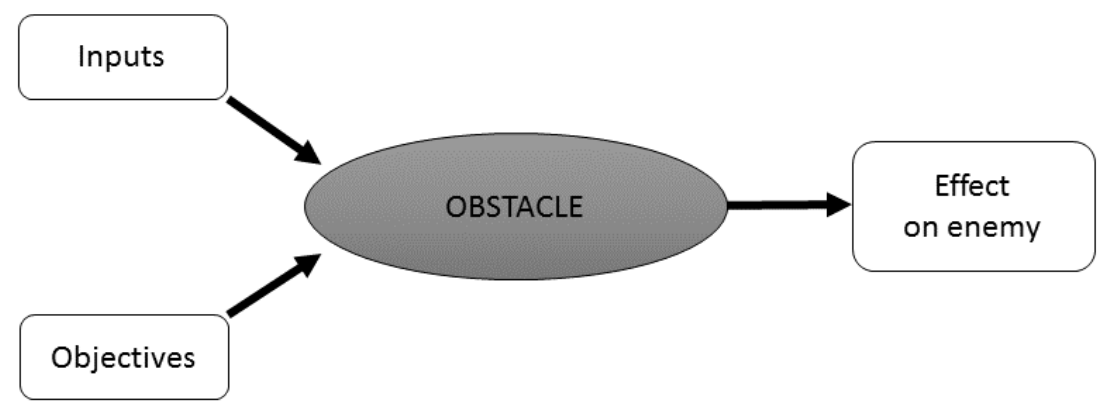

Figure 1: Expression of obstacle resolutions

Firstly, it is necessary to determine inputs that have, in varying degrees, influences on the requirements of obstacle effectiveness. Three basic elements are default:

- Own forces

- Enemy forces

- Terrain

In terms of our own forces it is necessary to take into account the strength and means that are available for obstacle emplacement. Especially the number of units and their level of training for conducting the tasks in obstacle emplacement, the amount of equipment and materials which will be directly involved in obstacle creation in the area and their tactical and technical options for the obstacle emplacement. It is also necessary to take into account the time that is available for obstacle creation and the restriction resulting from the legislative and managing documents. Thus, important data will be:

- Speed of obstacle creation (emplacement)

- Amount of means for obstacle creation (emplacement)
- Possible use of means in situation and terrain

- Possibility of means protection

- Possibility of cover barrier with fires

From the viewpoint of the enemy, it is necessary to take into account in particular the available means for breaching, their technical possibilities and rules for using these means. It is also important to take into account unit tactics and procedures within the area without the presence of barriers and the area where the barriers were detected. The main data will be:

- Speed of breaching

- Amount of breaching means

- Speed and method of moving in area without barriers

- Speed of gap-crossing

- Organization of gap-crossing

In the area of responsibility, where it intends to create barriers, it is necessary first of all to pay attention to the existing obstacles (rivers, urbanized areas, forests, etc.), condition and number of routes and objects. It is necessary to check up information about soil characteristics and possible local resources of material for 
obstacle creation. Important information relating to the obstacle creation are:

- Impact of terrain (obstacles) to activities (Mobility Corridors, Avenues of Approach)

- Possibility of terrain shaping

- Possibility of using local resources of material

\section{Evaluation criteria of obstacle effectiveness}

Expressing of barriers must be based on the general objectives of obstacle emplacement. Amongst these goals, according to current doctrines, include:

- Cause losses to enemy forces

- Restrict, slow down or stop the movement of the enemy

- Deny enemy to use areas that are advantageous for own units

- Create advantageous conditions for the destruction of enemy with firepower

It is necessary to choose the appropriate effectiveness criteria in order to express the level of objectives achievement of obstacle emplacement. It is necessary based on the actual participation of barriers to the fulfillment of those objectives. Effectiveness criteria of obstacle emplacement must allow expression of influence on result of enemy's activity inside area with obstacles against conditions without presence of obstacles. It is necessary to express the costs associated with obstacle emplacement (difficulty of creation) in terms of necessary inputs for real evaluation of obstacle effectiveness.

The difficulty of criteria determination for obstacle effectiveness evaluation is given by the needs expressed by a number of factors, which can work in certain conditions in varying degrees. Part of the criteria has general validity (apply to all kinds of barriers regardless of creation period). But a number of criteria can be applied only to certain types of barriers or has meaning only in relation to a period when it is possible to create the species barrier. It follows from custody barriers on the terrain, climate and weather conditions, the occurrence of material from local resources etc. It is necessary to define the meaning and extent to each criterion for effectiveness evaluation of obstacle emplacement, depending on specific conditions. The criteria, which in terms of practical importance in a particular situation need not to be considered, shall be determined on the basis of this delimitation. Basic evaluation criteria must unambiguously correlate with the objectives of barriers (Figure 2) and should reflect the effect of the barrier on the enemy. The criteria must be measurable to simplify the planning and evaluation of the obstacle effect for the use of automated command and control systems. 


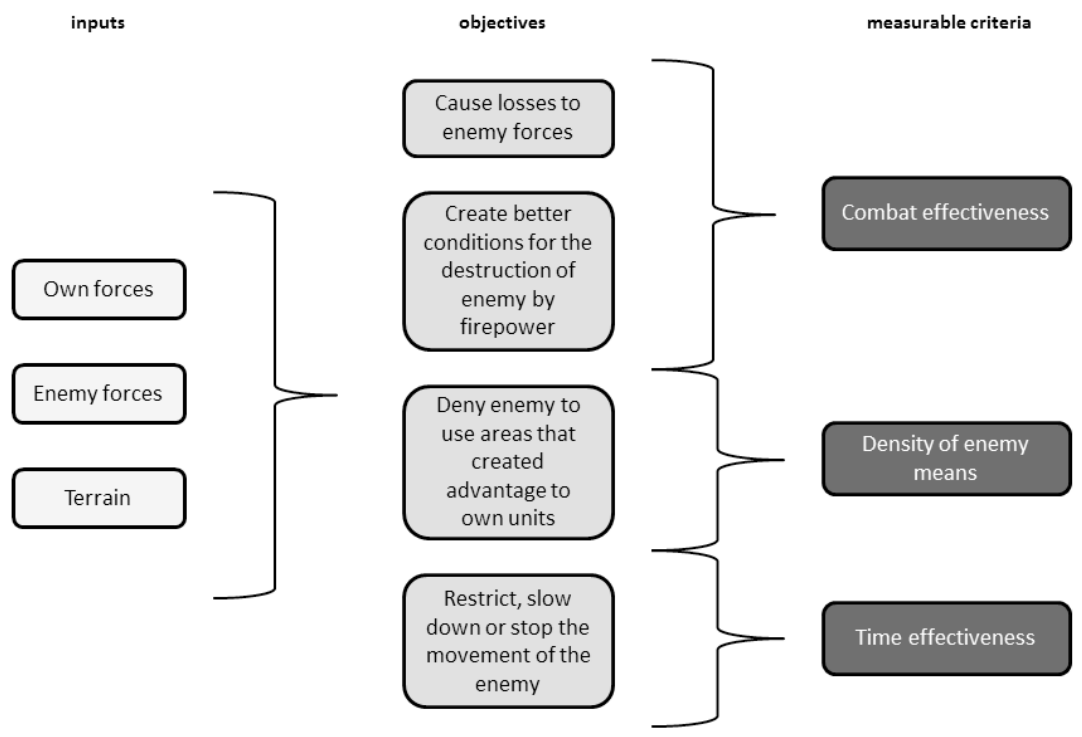

Figure 2: The relationship between inputs, objectives and criteria of barriers

The primary criterion for effectiveness evaluation of barriers is the number of destroyed (retained) combat vehicles or losses on the living power of the enemy combat effectiveness, which expresses ability of the obstacle to cause direct losses. Combat effectiveness can be mainly determined for explosive obstacles. This determination is difficult for unexploded obstacles, because most unexploded obstacles by their nature are not intended to causing direct losses to the enemy. In this case, it is obstacle participation in combat effectiveness of own fires. This participation expresses mediated effect of obstacle on efficient utilization of own firing systems.

Combat effectiveness is understood as conditional probability, because it ignores the many factors (eg. the probability of targets entering into a minefield, the probability of finding a minefield and breaching of gaps by enemy, the probability of operational reliability of landmines etc.). The value of combat effectiveness is ranging between 0 and 1 and gives a probability of target elimination in the minefield.

Another significant quantity that expresses the effect of the barrier is time. Time effectiveness plays an important role in influencing of enemy activities. The presence of the barrier disrupts the formation and tempo of the enemy, interrupts his schedule, restricts freedom of maneuver in the area, slows the enemy within a certain area, where can be identified, targeted and destroyed. Time effectiveness indicates the time required for enemy activity, which is associated with overcoming or removing an obstacle. Time effectiveness can be expressed as the time required for overcoming (removing) the obstacle by using the optimal way of overcoming (removing) obstacle (Figure 3). Difference between times $(\Delta T)$, needed to overcome the distance $\mathrm{L}$ in the area without the presence of obstacles and with obstacles, is the result of hold effect of obstacles, which created advantageous conditions for the destruction of the enemy forces. The time necessary for the breaching of an obstacle $\left(\mathrm{T}_{\mathrm{A}}\right)$ can be determined by the procedures and means that enemy can use. Time effectiveness can also be expressed according to the estimated values of depth of enemy penetration in the case of barriers presence on the direction of his movement and penetration in the event that obstacles are not on a given direction. 


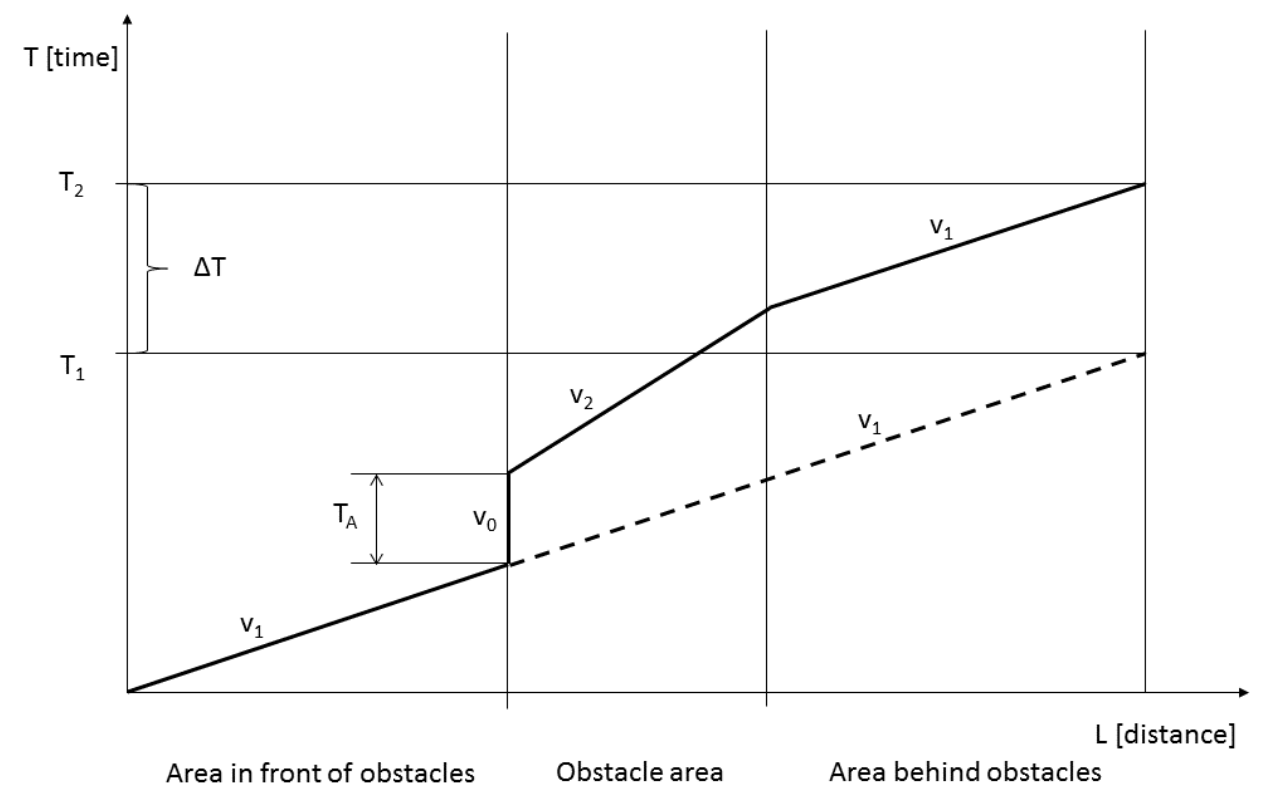

Figure 3: Schematic expression of obstacle time effectiveness

Another important criterion, which reflects the effect of obstacles on the enemy, is the restriction in the use of areas. The presence of barriers disrupts enemy not only during movement, but also on the front edge and in the depth of the area of deployment (responsibility). Barriers restrict the possibilities of maneuver and possibilities for deployment of troops in the area, channel the enemy into areas that are advantageous for its destruction, and create the conditions to keep decisive areas, which may significantly influence the battle.

To express this criterion, it is necessary to know the principles of tactics and procedures of enemy forces. Based on this knowledge, it is possible to determine the fulfillment of the criterion as a ratio between the amount of enemy means in a given area without the presence of obstacles and the amount of enemy means in a given area with obstacles. Simply we can say that there is a ratio of the density of means in area with obstacles $\left(\mathrm{H}_{\mathrm{z}}\right)$ and without them $\left(\mathrm{H}_{0}\right)$ :

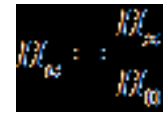

where just the density of means within the area without the presence of obstacles is the value, which is based on the principles of tactical use of enemy means in battle.

\section{Conclusion}

Barriers provide a significant advantage in the operational area in the fulfilment of tasks in military operations. They play a role in providing protection of deployed forces and obstruct enemy to use of important areas and communications regardless of the type of operation. Barriers are used to restrict the movement of enemy forces, increase the effectiveness of own fires, restrict the use of terrain, disrupt the sustainability of forces and cause losses of enemy forces.

For each operation, it is necessary to determinate appropriate criteria for evaluating the effectiveness of barriers for assessing the desired effect on the enemy. These criteria must be consistent with the general objectives of obstacle emplacement. By an analysis of individual objectives, for the basic criteria can be considered:

- Combat effectiveness

- Time effectiveness

- Density enemy means in a given area Combat effectiveness is the ability of obstacle to cause losses to enemy on combat means and manpower, either as direct losses on explosive obstacles or indirectly, when the obstacle allows the destruction of enemy forces by own fires. Time effectiveness is the ability of obstacle 
to retain (stop) enemy forces for a certain period and where success is achieved by reducing enemy tempo of movement.

Density of enemy means represents the ability of obstacle in limiting the use of area, or the grouping enemy in areas that are suitable for the destruction of enemy forces with own fires.

These criteria can be, depending on the type of operation, situation, terrain, means available and other factors, supplemented by additional, e.g. the possibility of direct influence of situation, time influence of obstacle, psychical effectiveness, usability in various conditions, the possibility of further use of the material, etc.

Effectiveness evaluation of obstacles plays an important role in the planning and management of military engineering. During the planning, effectiveness criteria of evaluation are useful for determining the parameters of barriers. Based on this determination it is possible to calculate the necessary time, manpower and means for obstacle emplacement. During the battle, effectiveness criteria of evaluation are useful for assessment (validation) of planned (predicted) enemy activity.

Based on the evaluations, using of basic and other criteria, it can determine the appropriate means requirements for obstacle emplacement. These requirements are applicable for further development of means and procedures of obstacle emplacement.

\section{References}

[1] AJP-3.2. Allied Joint Doctrine for Land Operations. Brussels: NSO, 2016.

[2] Žen-2-9. Ženijní práce všech druhů vojsk. Praha: Ministerstvo národní obrany, 1981.

[3] AJP-3.12(B). Allied Joint Doctrine for Military Engineering. Brussels: NSO, 2014.

[4] ATP-3.12.1. Allied Tactical Doctrine for Military Engineering. Brussels: NSO, 2016. 